\title{
Suspeita de úlcera gástrica em equino submetido a confinamento
}

Danielle Araújo Barbosa;, Homero Leite Martins, Frederico Fernandes Araújo, Mariana Cosenza, Daniela Maria Schueroff, Lucas Ruan Pires

Centro Universitário Filadélfia (Unifil), Londrina, PR, Brasil

*Autor correspondente

e-mail: danielle.cristina.araujo@hotmail.com

\section{Resumo}

A síndrome cólica é uma das principais enfermidades que acometem os equinos, sendo mais comum as dores de origem gastrointestinais. É considerada uma doença grave, com evolução rápida e que pode levar o animal a óbito se não for dado o devido tratamento. É importante ter o conhecimento dos potenciais fatores que desencadeiam a síndrome cólica, para entender a etiologia e o quadro clínico em que o animal se encontra e realizar tratamento adequado para cada caso. As cólicas podem ser de diferentes etiologias, entre elas obstruções, compactações, torções, as de origem estomacais como úlceras gástricas e outras diversas causas. As úlceras gástricas podem estar associadas ao confinamento, estresse, idade, sobrecarga de trabalho, uso abusivo de anti-inflamatórios não esteroidais, mudanças no manejo, dietas inadequadas e infecção por Helicobacter spp. Um equino macho de 1 ano e 8 meses chegou ao hospital veterinário da UniFil apresentando ausência de motilidade intestinal, frequência cardíaca (FC) de 88 bpm, temperatura de $37,4^{\circ} \mathrm{C}$, mucosa hiperêmica e tempo de preenchimento capilar (TPC) de 5". Na anamnese, o proprietário relatou que $\mathrm{o}$ animal foi adquirido em leilão. 0 equino ficava solto em piquetes e quando chegou em sua propriedade foi mantido na baia durante a maior parte do tempo, recebendo ração e feno duas vezes ao dia, e sendo solto poucas vezes. Antes de o animal chegar ao hospital, foram realizados alguns procedimentos na propriedade, pois o animal iniciou com desconforto abdominal por volta das 18:00 horas do dia anterior; os procedimentos incluíram a dissolução de pó de café em 1 litro de água e $50 \mathrm{~mL}$ de óleo de oliva, por via oral, feita por uma pessoa não capacitada. 0 veterinário administrou $10 \mathrm{~mL}$ de flunixin meglumine, $60 \mathrm{~mL}$ de Sedacol ${ }^{\circledR}$ pela via intravenosa. Depois de 1 hora, foi feito o 1 litro de soro fisiológico com $120 \mathrm{~mL}$ de Merceptom ${ }^{\circledR}$ e $120 \mathrm{~mL}$ de Sedacol ${ }^{\circledR}$ pela via intravenosa. Na propriedade, o médico veterinário realizou a lavagem do estômago, de onde foram retirados 2 litros de refluxo e aplicado $25 \mathrm{~mL}$ de dipirona intravenosa. No hospital veterinário, para tratamento inicial do animal, foi realizada a sondagem nasogástrica, obtendo 13 litros de refluxo 
espontâneo sanguinolento estomacal, contendo presença de feno e ração; foi feita, então, lavagem gástrica com água para auxiliar na remoção do conteúdo estomacal. Realizou-se a palpação transretal, onde foi possível sentir intestino delgado distendido. Na paracentese, foi obtido uma amostra de $3 \mathrm{~mL}$ de coloração amarelada e aspecto turvo, com 91\% de segmentados, sendo indicativo de lesões enterogástricas. No hemograma, apresentou fibrinogênio de $400 \mathrm{mg} / \mathrm{dL}$ (100-400 mg/dL), indicando reação inflamatória. Após o atendimento inicial, o animal apresentava hipomotilidade intestinal, FC de 56 bpm, mucosa hiperêmica e TPC de 4". Por via oral, foi administrado $80 \mathrm{~mL}$ de sucralfato e Gastrozol ${ }^{\circledR}$. Antibioticoterapia foi realizada com ceftiofuor $5 \mathrm{mg} / \mathrm{kg}$ intravenoso durante 5 dias, e fluidoterapia com ringer lactato totalizando 20 litros por via parenteral. Com a anamnese, sinais clínicos e a resposta positiva ao tratamento, a principal suspeita foi úlcera gástrica. A gastroscopia não foi realizada pois não há profissionais que realizem o serviço na região. Com o presente trabalho, concluiu-se que a mudança abrupta de hábito alimentar, com grande quantidade de carboidratos, e o confinamento, que leva ao estresse, podem ter induzido o animal a desenvolver uma úlcera gástrica. 0 tratamento realizado no hospital foi eficiente, mas sabe-se que esse animal irá necessitar de um manejo adequado para que o quadro clínico não se repita. Foi prescrito, após a alta médica, diminuir a quantidade de concentrado, soltar o animal por períodos mais longos e mais vezes ao dia e administrar omeprazol durante 50 dias. É importante ressaltar que mudanças abruptas no manejo de equinos podem levar a quadros graves de gastrite e a outras alterações gastrointestinais.

Palavras-chave: Cólica. Hipomotilidade intestinal. Refluxo espontâneo. 